\title{
Effect of Gamma Rays on Seed Germination, Survival Rate and Morphology of Stevia rebaudiana Hybrid
}

\author{
Shamsiah Abdullah ${ }^{a, *}$, Nor Yasmin Mohamad Fauzi ${ }^{a}$, Aida Khalida Khalid ${ }^{a}$, \\ Mohamad Osman ${ }^{\mathrm{b}}$, Azhar Mohamad ${ }^{\mathrm{c}}$
}

a Faculty of Plantation and Agrotechnology, Universiti Teknologi MARA, Cawangan Melaka Kampus Jasin, 77300 Merlimau; Melaka; ${ }^{b}$ Atri Advisory, Jalan Ampang, 50450 Kuala Lumpur, Malaysia; ${ }^{\mathrm{c}}$ Agrotechnology \& Bioscience Division, Agensi Nuklear Malaysia, Bangi 43000 Kajang, Selangor Darul Ehsan, Malaysia
*For correspondence: shamsiah3938@uitm.edu. my

Received: 13 February 2021 Accepted: 15 October 2021

(C) Copyright Azman. This article is distributed under the terms of the Creative Commons Attribution License, which permits unrestricted use and redistribution provided that the original author and source are credited
Abstract The effects of gamma radiation are investigated by studying seed germination, survival rate and morphological characteristics of Stevia rebaudiana. Improvement of stevia plant through mutagenesis could be one of the ways to produce stevia with delay flowering. Currently, stevia varieties in Malaysia exhibit early flowering because they received day length less than 13 hours. In this study, seeds of stevia hybrid, $\mathrm{H} 2$, are exposed to gamma irradiation doses at 0,100 , $300,500,700,900$ and $1100 \mathrm{~Gy}$. Our results show that the germination and survival rate, as well as morphological parameters of stevia decreased by increasing the irradiation dose. Moreover, irradiated seeds exposed to higher doses ( $>500 \mathrm{~Gy}$ ) failed to germinate. Based on the survival percentage vs gamma doses, the calculated lethal dose was $323 \mathrm{~Gy}$, which will allow obtaining promising stevia mutants. The plant height and number of leaves in irradiated plant obtained were highest in treatment $100 \mathrm{~Gy}, 13.50 \pm 7.48 \mathrm{~cm}$ and $16.00 \pm 7.66$ respectively. Meanwhile, the length of leaves recorded was highest in treatment $300 \mathrm{~Gy}(3.00 \pm 0.89 \mathrm{~cm})$. Analysis on the chemical content and molecular level of the irradiated plant for future work are useful to verify the changes due to the radiation. Gamma irradiation is a promising alternative to obtain a greater stevia variability for advanced mutant lines.

Keywords: Gamma ray; germination, mutagenesis; radiosensitivity test; Stevia rebaudiana.

\section{Introduction}

Stevia rebaudiana is originated from South America, specifically in Brazil and Paraguay belongs to Asteraceae family that consists of more than 50,000 species of perennials herbs and shrubs. This plant is mostly grows at altitudes of 500 to 3000 metres in semi dry mountain areas and also can grow in scrub forests, grassland and sub-alpine area [1]. Stevia rebaudiana is also known as honey leaf, sweet leaf or sugar leaf and it is one of the 300 species of the genus. It is classify as herbs and considers as a good substitute for sugar. It is a type of sweetener that difficult to digest in the human digestive tract because of the compounds cannot be chemically breaking down. Thus, it constitutes a safe sweetener for human health especially for diabetic patients [2]. Stevia rebaudiana leaves contain steviol glycosides compound, which are stevioside and rebaudioside A. These two compounds have insulin balancing properties and good for human health [3]. The steviol glycosides compound is responsible for the sweet taste of the Stevia rebaudiana leaves. The stevia products were commercially produced to replace sugar and can be added to tea and coffee, processed foods, pastries, chewing gum, pickles, fruit juices, confectionary 
goods, cooked or baked goods, jams and jellies, candies, yogurts, sherbets beverages, and tobacco products [4].

The low seed germination rate of Stevia rebaudiana in the range of $10 \%$ to $36.3 \%$, is one of the issues in the production of stevia on a large-scale basis [2]. Due to the low seed germination rate in Stevia rebaudiana, performing a task to test the seed viability and germination rate is crucial. Another characteristic of stevia is, a short-day plant, hence it requires at least 13 hours to avoid early flowering which eventually affect the amount of sweet compounds that can be extracted from its leaf. When stevia receives light in less than 13 hours, this situation will induce early flowering and less leaves are produced which affect the amount of steviol glycosides that can be harvested from the leaves. Previous reports showed that the amount of steviol glycosides content decreased as the stevia received day length less than 13 hours [5][6][7].

Light has fundamentally two functions during development and growth of Stevia rebaudiana. Mainly, light will allow plant growth such as the stem thickness, rooting formation and number of branches through the photosynthesis process [8]. Next, light also involved in some developmental processes such as seed germination and flowering. Growers can manipulate the length of the day to enhance the sensitivity during flowering photoperiod and create simulated lighting to a crop to increase plant growth and the rate of photosynthesis. Stevia rebaudiana is a restricted short days plant with a critical day length require about 13 hours. As for stevia requires short days for flowering to occur. Some study has found that some plants that flower earlier when grown under short days will have delayed flowering if exposed to long days [8].

As the awareness of consumption of stevia grows rapidly, the long day length requirement for stevia to grow has becoming the crucial factor for stevia production. This is due to the critical length of certain country which did not meet the requirement of the optimal yield of stevia. Therefore, the genetic improvement of this type of crop is crucial to overcome the early flowering of stevia. The genetic improvement of plant through mutation breeding is getting a tremendous attention by researchers around the world [9]. Genetic improvement in many crops todays is often directed for producing a new variety that is resistance towards diseases and pest [10]. Different in stevia, the genetic transformation programme aim at producing a new variety that exhibit better capacities in yielding sweet compound for utilization as a natural sweetener. However, lack of suitable varieties that can sustain the vegetative phase in Malaysia have made the stevia commercialization encounter issue in the supply of raw material. At this point, mutation breeding through gamma irradiation is expected to give significant effect in establishment of new stevia variety with improved characteristics.

Research on the basic interaction of ionizing radiation with biological system has contributed to human society through many ways such as agriculture. Induced mutation using gamma radiation is largely applied to increase crop yield, quality of crop, and plant disease and pest resistance since 1960's. Many genetic materials with novel and desired traits and characteristics are produced using this method. Mutation breeding findings that the medium used to study the nature creation and function of genes which are basis of plant growth and plant development [4]. Many crops have been established since the mutation breeding applied for improvement of crops [11] such maize, cowpea, potato, rice, barley and soybean.

Gamma irradiation is an example of approach in physical induced mutation. It is reported to be the most efficient ionizing radiation of producing mutants in plants as they can increase the mutation rate. Gamma irradiation alter the physiological traits to make new mutants with improved and better properties. As the results, creating new varieties for agriculture sector, the plant produces higher amounts of essential metabolites, economically significant for commercialization and higher production of yield. Gamma irradiation also controls influence in protein patterns by inducing appearance or disappearance of some protein bands. Mutagen works in term of gene alteration or chromosomal aberration. The error in DNA sequence occurs when a plant treated with mutagen treatment, some error will be fixed. However, the error that is not being fixed will be passed to the offspring and become spontaneous mutation [10]. As reported in previous study, the mutation breeding is applied for improvement of agronomic traits such as 
early maturation, yield, and pest resistance [11].

The current research was conducted to determine the effect of gamma ray on germination rate, seedling survival and the morphological characters such as plant height, leaves number and leaves length of Stevia rebaudiana hybrid, $\mathrm{H} 2$. Based on the survival rate, the effective dose $\left(\mathrm{LD}_{50}\right)$ was calculated for this hybrid.

\section{Materials and methods}

\section{Plant material preparation}

Stevia hybrid designated $\mathrm{H} 2$, has been used for the present study. One hundred dry seeds were irradiated with gamma rays with various doses of 100, 300, 500, 700, 900 and 1100 Gy using Biobeam GM 8000 located at Malaysia Nuclear Agency. The source of gamma facility used was Caesium 137 (Cs-137) with 4.42 min per $100 \mathrm{~Gy}$. After irradiation, twenty seeds of each dose were then sown in pots. Non irradiated seeds were used as control treatment ( $0 \mathrm{~Gy}$ ). Data was calculated by taking the random plant samples for each trait.

\section{Germination rate, survival rate and other morphological characteristics}

Data on as seed germination rate, plant survival and selected morphological characters such seedling height, leaves number and leaves length have been recorded and compared with control. The data on seed germination was recorded right from the emergence of first shoot in each treatment including control. Germination percentage was determined by counting the seedlings emerged in each pot per total number of seeds sown, multiplied by hundred.

Seedling height was measured started on 7th day after germination by measuring the irradiated and nonirradiated of randomly from each treatment. The height was measured from the base of the plant to the tip of flag leaf. Number of leaves was recorded for each leaf developed and length of leaves was measured on fully expanded leaf. Recorded data was analysed to assess the extent of induced variations.

\section{Statistical analysis}

All data were analysed using SPSS statistical analysis software version. The mean was compared by one-way ANOVA analysis through Tukey test.

\section{Results and discussion}

\section{Seed germination and survival rate}

The percentage germination of stevia seeds, irradiated with varied doses of gamma ray were presented in Table 1. Germination rates on irradiated seeds ranged between 0 to 1100 Gy, achieving $100 \%$ rate of germination. According to [12] germination remain quite complex to evaluate because several independent factors like temperature, light, oxygen and water affects each stage of the germination process in different ways. If these factors are adequately available, each determines a fraction of the germinated seeds and the rate of the germination [13]. Based on the analysis, seed germination rate did not show significant differences between treatments.

The different observations were obtained on the survival of germinated seeds, where seedlings from treatment 700, 900 and 1100 Gy did not survive 7 days after germination (Figure 1). The survival percentage decreased as the irradiation doses increased. Non-irradiated stevia seeds show $100 \%$ percentage of survival. Based on the results, the higher the gamma doses exposed to the seeds, the lower the survival rate of the seeds. The seeds exposed to 100 Gy showed $66.7 \%$ of survival. Meanwhile, the lowest percentage of survival recorded in 500 Gy (26.7\%). Thus, the $\mathrm{LD}_{50}$ obtained by plotting the survival rate vs. gamma radiation doses was $323 \mathrm{~Gy}$ (Figure 1). Survival percentages were negatively affected as the dose increased, due to the 
persistence of damaged DNA having a significant growth-inhibitory influence [14]. In addition, higher irradiation doses (500 and $600 \mathrm{~Gy}$ ) are lethal because they destroy genes or metabolites involved in seed germination and/or plant growth and induce undesirable modifications of chromosomal structures inhibiting the expression of genes involved in the cell cycle [15].

Table 1. Effect of gamma irradiation on seed germination rate

\begin{tabular}{cc}
\hline Treatment/Doses (Gy) & Germination Rate (\%) \\
\hline 0 & $100 \mathrm{a}$ \\
100 & $100 \mathrm{a}$ \\
300 & $100 \mathrm{a}$ \\
500 & $100 \mathrm{a}$ \\
700 & $100 \mathrm{a}$ \\
900 & $100 \mathrm{a}$ \\
1100 & $100 \mathrm{a}$ \\
\hline
\end{tabular}

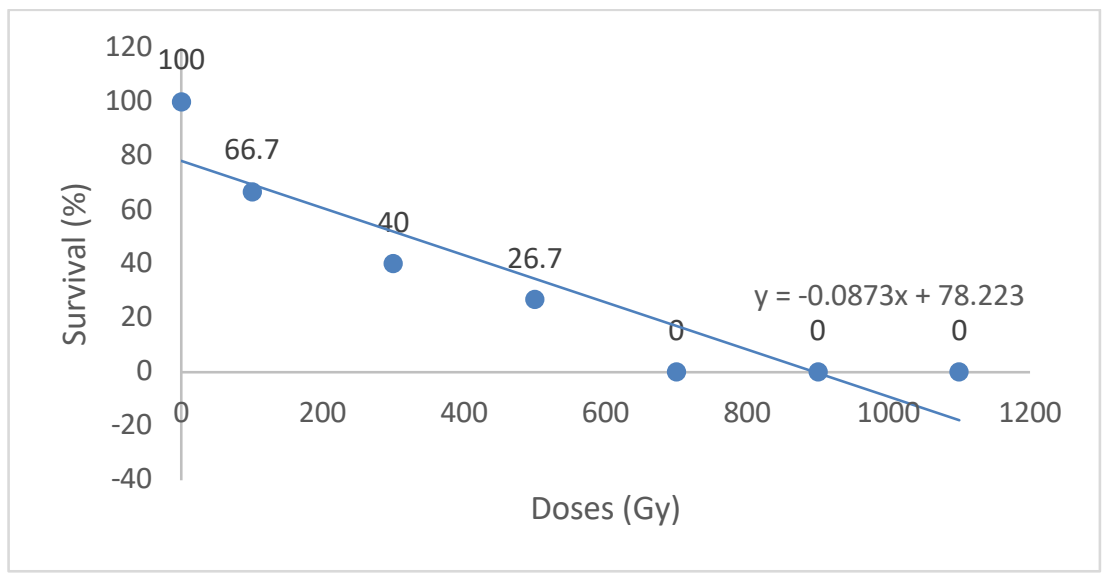

Figure 1. The survival rate (\%) against gamma dose (Gy) of $\mathrm{H} 2 \mathrm{Hybrid}$ Stevia irradiated with gamma ray to determine the $L D_{50}$.

\section{Plant height}

Plant height is widely used as an index in determining the biological effects of physical mutagens. In the present investigation, the average plant height was observed higher in control population $(16.57 \mathrm{~cm})$ and gamma rays decreased this average height to 10.50 at the $500 \mathrm{~Gy}$ radiation dose (Table 2). All the doses showed decrease in the average plant height and showed inverse proportionality to the radiation intensity.

The highest plant height was recorded in control treatment ( $0 \mathrm{~Gy}$ ) with $16.57 \pm 6.14$. However, there was no significant difference in height of control treatment compared to other irradiated stevia plant. The lowest plant height recorded was in 500 Gy treatment. No results obtained for stevia plant in treatment 700, 900 and $110 \mathrm{~Gy}$ as no seedling survived from the treatments. This result showed that increasing gamma irradiation doses has caused slow height increment. Previous study has recorded the negative effects of high dosage of gamma irradiation. As reported by [17] high dose of gamma irradiation exposure led to necrosis of in vitro explant and affect the callus growth. As result, the stevia plant was stunted and not well developed. This trend might be due to the higher dose of gamma exposure causes the decreasing in mitotic activity in meristem tissue and reduction in moisture content in the stevia plant [10]. 
As mentioned by previous researcher [18], the roots that showed depletion of growth rate is resulted from the declining of production of new cells due to mitotic activity in apical meristem and obstruction of extension in elongation parts. This statement supported the fact that reduction in mitotic activity is related to the plant height since the production of new cells is disrupted as the mitotic activity reduced.

Table 2. Effect of gamma irradiation on plant height, number and length of leaves after three months of transplanting

\begin{tabular}{cccc}
\hline Doses (Gy) & Plant height $(\mathrm{cm})$ & No of leaves & length of leaves $(\mathrm{cm})$ \\
\hline 0 & $16.57 \pm 6.14 \mathrm{a}$ & $16.33 \pm 5.89 \mathrm{a}$ & $2.94 \pm 0.64 \mathrm{a}$ \\
100 & $13.50 \pm 7.48 \mathrm{~b}$ & $16.00 \pm 7.66 \mathrm{a}$ & $2.88 \pm 1.48 \mathrm{a}$ \\
300 & $12.08 \pm 1.28 \mathrm{~b}$ & $13.50 \pm 4.57 \mathrm{~b}$ & $3.00 \pm 0.89 \mathrm{a}$ \\
500 & $10.50 \pm 3.70 \mathrm{ab}$ & $12.75 \pm 5.74 \mathrm{~b}$ & $2.25 \pm 0.98 \mathrm{a}$ \\
700 & $00.00 \pm 00.00$ & $00.00 \pm 00.00$ & $00.00 \pm 00.00$ \\
900 & $00.00 \pm 00.01$ & $00.00 \pm 00.01$ & $00.00 \pm 00.00$ \\
1100 & $00.00 \pm 00.02$ & $00.00 \pm 00.02$ & $00.00 \pm 00.00$ \\
\hline
\end{tabular}

\section{Number of leaves and leaves size}

For the number of leaves, highest results observed were in treatment 0 Gy (control) and 100 Gy with the average of $16.33 \pm 5.89$ and $16.00 \pm 7.66$ respectively. The lowest number of leaves recorded was in the treatment of $500 \mathrm{~Gy}(12.75 \pm 5.74)$. There is no significant difference in leaves number between the control treatment and treatment $100 \mathrm{~Gy}$ but there is significant difference with treatment 300 and $500 \mathrm{~Gy}$. These results showed after gamma irradiation exposure with low dose of mutagen treatment can stimulate the growth and development of leaves. Irradiated stevia plant from treatment $300 \mathrm{~Gy}$ showed the highest leaves length $(3.00 \pm 0.89 a)$, however there is not significant different between treatments. Meanwhile, plant from treatment $500 \mathrm{~Gy}$, showed the lowest length of leaves $(2.25 \pm 0.98 \mathrm{a})$. No results obtained for stevia plant in treatment 700,900 and 110 Gy as no seedling survived from these treatments. These results clearly showed that higher gamma dose can cause cell death and thus, lead to low growth performances of irradiated plants. Based on the previous study, low doses of gamma irradiation are good for germination and plant development, meanwhile, high dose of gamma would lead to growth dissimilarities, slow down the emergence and eventually led to death of irradiated plants [18][19].

(a)

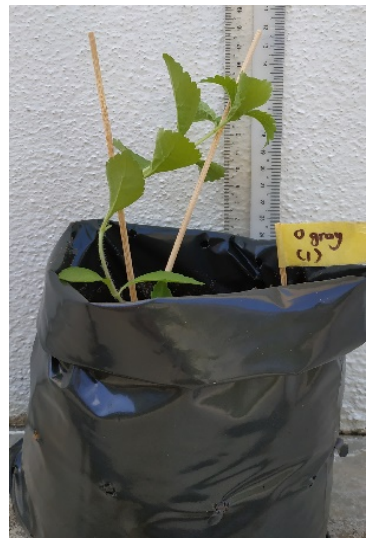

(b)

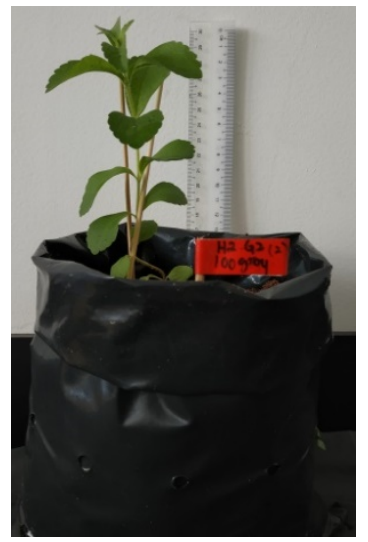

(c)

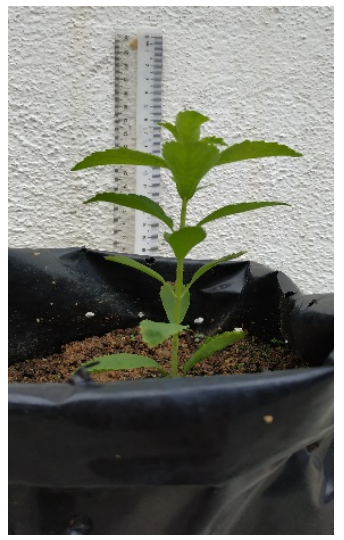

(d)

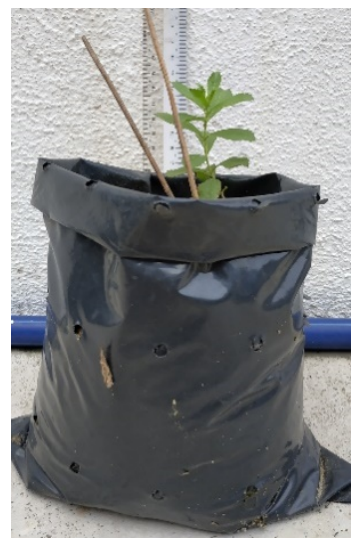

Figure 2. Differences between irradiated and non-irradiated H2 Hybrid Stevia (a) 0 Gy, (b) 100 Gy, (c) 300 Gy, (d) 500 Gy

Gamma irradiation has previously reported to change the morphology, anatomy, biochemistry, and physiology of plant depending on irradiation dose [20]. In the present study, the irradiated plants showed no significant difference in plant height. However, they have produced larger leaves size and higher 
number of leaves per plant (Figure 2). As reported by [17][21], the gamma irradiation has successfully improved root length, leaves number and the plant development.

Based on the results of the morphological parameter, gamma irradiation changes the character of a plant as it can affect the cell wall and cell membrane and thus, the high dose exposure to gamma irradiation can cause depletion in tissue growth [22]. Similar study has found that the regeneration frequency in Stevia rebaudiana reduced because of the endogenous hormonal level in leaf explant due to high dose of gamma irradiation [22].

A study on wheat plant by [23] was conducted to decrease the plant height using gamma irradiation. Form the study, it was found that the used of high gamma dosage is possible which high dose of gamma has produced wheat with low height and high grain yield. This shows that changes in certain character is not necessary change the other character such as yield. Since steviol glycosides normally high in leaves, the number of leaves and leaves size as affected by the various doses of gamma ray is important to be recorded for each plant.

\section{Conclusion}

Generally, retardation of morphological and growth parameters is one of the most common responses of plant subjected to ionizing radiation. The study reveals how hybrid stevia, $\mathrm{H} 2$, response to gamma radiation. Lower doses of gamma irradiation (100 \& $300 \mathrm{~Gy}$ ) induce positive morphological changes in stevia, while higher doses (above $500 \mathrm{~Gy}$ ) negatively affect plant growth and survival due to deleterious effects such as chromosomal damages, which reduce the stability of the plant genome. The calculated $\mathrm{LD}_{50}(323 \mathrm{~Gy}$ ) was obtained based on the survival percentage vs gamma doses, suggesting that it could be successfully used in the future for its improvement in which a greater genetic variability is expected to be obtained in advanced mutant lines.

\section{Acknowledgments}

This research work is supported by Ministry of Higher Education Malaysia under the research grant FRGS 1/2016. The authors would like to thank Universiti Teknologi MARA (UiTM) for the GIP research grant and Nuclear Malaysia Agency for the support of gamma radiation facility for this research.

\section{References}

[1] M. Serfaty, M. Ibdah, R. Fischer, et al., "Dynamics of yield components and stevioside production in Stevia rebaudiana grown under different planting times, plant stands and harvest regime," Industrial Crops and Products, vol. 50, pp. 731-736, 2013.

[2] R. A. Abdullateef, M. Osman and Z. Zainuddin, "Acclimatized apparatus enhanced seed germination in Stevia rebaudiana Bertoni," International Journal of Biology, vol. 7, no. 2, pp. 28, 2015.

[3] S. Pande and M. Khetmalas, "Effect of gamma irradiations on seed germination and seedling survival of Stevia rebaudiana Bert.," South Asian Journal of Experimental Biology, vol. 1, no. 6, pp. 255-259, 2011.

[4] N. Noordin, R. Ibrahim, N. H. Mohd Sajahan, S. Moosa and S. Hussein, "Effects of acute and chronic gamma irradiation on in vitro growth of Stevia rebaudiana Bertoni" Agrotechnology and Biosciences Division, Malaysian Nuclear Agency, Ministry of Science, Technology and Innovation Malaysia (MOSTI).

[5] M. S. Chiew, K. S. Lai, S. Hussien, S. and O. J. Abdullah, "A Review on induced mutagenesis of Stevia rebaudiana Bertoni," Pertanika Journal of Scholarly Research Review, vol. 2, no. 3, pp. 77-85, 2016.

[6] P. Kashiani, G. Saleh and R. Rus, "Performance and genetic diversity among a collection of Stevia rebaudiana Bertoni accessions using microsatellite markers in Malaysia. Multidisciplinary Digital Publishing Institute Proceedings, vol. 36, no. 1, pp. 221, 2020.

[7] J. LeCroy, "Factors affecting seed and stem cutting propagation of Stevia rebaudiana Bert.," Doctoral dissertation, 2014.

[8] R. A. Abdullateef, and M. Osman, "Influence of Genetic Variation on Morphological Diversity in Accessions of Stevia rebaudiana Bertoni," International Journal of Biology, vol. 3, no. 3, 2011, pp. 66-72.

[9] A. Raina, R. A. Laskar, S. Khursheed, et al., "Role of mutation breeding in crop improvement-past, present and 
future," Asian Research Journal of Agriculture, pp. 1-13, 2016.

[10] F. J. Novak and H. Brunner, "Plant breeding: Induced mutation technology for crop improvement," IAEA Bull, vol. 4, pp. 25-33, 1992.

[11] S. Y. Kang, D. S. Kim and G. D. Lee, "Genetic improvement of crop plants by mutation techniques in Korea," Plant Mutation Reports, vol. 1, no. 3, pp. 7-15, 2007.

[12] K. C. Gairola, A. R. Nautiyal and A. K. Dwivedi, "Effect of temperature and germination media on seed germination of Jatropha curcas Linn.," Adv. Bio-Res., vol. 2, pp. 66-71, 2011.

[13] D. Dhakhanamoorthy, R. Selvaraj and A. Chidambaram, "Physicla and chemical mutagenics in Jatropha curcas L. to induce variability in seed germination, growth and yield traits," Rom. J. Plant Biol., vol. 55, pp. 11325,2010

[14] V. Manova and D. Gruszka, "DNA damage and repair in plants from models to crops," Front Plant Sci., vol. 6, pp. 885, 2015.

[15] M. Saraswathi, G. Kannan, S. Uma, R. Thangavelu and S. Backiyarani, "Improvement of banana cv. Rasthali (Silk, AAB) against Fusarium oxysporum f.sp. cubense (VCG 0124/5) through induced mutagenesis: Determination of $\mathrm{LD}_{50}$ specific to mutagen, explants, toxins and in vitro and in vivo screening for Fusarium wilt resistance," Indian J Exp Biol., vol. 54, pp. 345-353, 2016.

[16] J. E. Brandle, A. N. Starratt and M. Gijzen, "Stevia rebaudiana: its agricultural, biological, and chemical properties," Canadian Journal of Plant Science, vol. 78, no. 4, pp. 527-536, 1998.

[17] S. Pande and M. Khetmalas, "Biological effects of gamma irradiation on in vitro culture of Stevia rebaudiana," Indian Journal of Applied research, vol. 1, no. 2, 2011, pp. 11-12.

[18] A. Fusconi, O. Repetto, E. Bona, et al., "Effects of cadmium on meristem activity and nucleus ploidy in roots of Pisum sativum L. cv. Frisson seedlings," Environmental and Experimental Botany, vol. 58, no. 1-3, pp. 253260, 2006.

[19] A. Majeed, Z. Muhammad and R. Ali, "Gamma irradiation, effect on germination and general growth characteristics of plants," Pakistan Journal of Botany, no. 50, vol. 6, pp. 2449, 2018.

[20] N. A. Hasbullah, R. M. Taha, A. Saleh and N. Mahmad, "Irradiation effect on in vitro organogenesis, callus growth and plantlet development of Gerbera jamesonii," Horticult Brasil, vol. 30, pp. 252-257, 2012.

[21] T. Charbaji and I, Nabulsi, "Effect of low doses of gamma irradiation on in vitro growth of grapevine," Plant Cell Tissue Organ Cult., vol 57, pp.129-132, 1999.

[22] S. A. Khan, L. U. Rahman, R. Verma and K. Shanker, "Physical and chemical mutagenesis in Stevia rebaudiana: variant generation with higher UGT expression and glycosidic profile but with low photosynthetic capabilities," Acta Physiologiae Plantarum, vol. 38, no. 1, pp. 1-12, 2016.

[23] N. Mashev, G. Vassilev, and K. Ivanove, "A study on N-alyl N-2 pyridyl thiourea and gamma radiation treatment on growth and quality of peas and wheat," Bulgarian Journal of Plant Physiology, vol. 21, no. 4, pp. 56-53, 1995. 